\title{
Diagnosis and therapeutic management of malasseziosis in dogs
}

\author{
K. Daniel Anju ${ }^{1}$, P. Vinu David ${ }^{2}$, Chintu Ravishankar ${ }^{3}$, \\ O.K. Sindhu ${ }^{2}$ and S. Ajithkumar ${ }^{4}$ \\ Department of Veterinary Clinical Medicine, Ethics and Jurisprudence \\ College of Veterinary and Animal Sciences, Pookode, Wayanad- 673576 \\ Kerala Veterinary and Animal Sciences University, Kerala, India
}

Daniel, A. K., David, V. P., Ravishankar, C., Sindhu O. K. and Ajithkumar, S. 2021. Diagnosis and therapeutic management of malasseziosis in Dogs. J. Vet. Anim. Sci. 52(3): 262-266.

DOI: https://doi.org/10.51966/jvas.2021.52.3.262-266

Received:21.01.2021

Accepted: 18.03.2021

Published: 30.09.2021

\begin{abstract}
Malassezia spp. are commensals of the normal cutaneous microbiota of humans and animals. These yeasts may become opportunistic pathogens under certain conditions and cause dermatitis and otitis externa in dogs. Malassezia pachydermatis is the most common cause of malasseziosis in dogs. In this study skin and ear swabs from suspected cases were cultured on Modified Dixon's Agar (MDA). The isolates obtained were initially characterized on the basis of colony characteristics, result of Gram staining and microscopic morphology. Total DNA was extracted from the pure cultures of the isolates and subjected to confirmation by polymerase chain reaction (PCR) targeting large subunit ribosomal RNA gene. Positive cases were treated with oral itraconazole at $5 \mathrm{mg} / \mathrm{kg}$ bodyweight, orally once daily for 28 days.
\end{abstract}

Keywords: Malassezia pachydermatis, MDA, PCR

Members of the genus Malasseziaare lipophilic basidiomycetous yeasts, which are part of the normal cutaneous microbiota of humans and other warm blooded animals. Malasseziosisis recognized as a secondary complication to other conditions like keratinization defects, hypersensitivity disorders, staphylococcal pyoderma and endocrinopathies. Itraconazole is a keratinophilic and lipophilic triazole antifungal agent used to treat malassezia infection (Pinchbeck et al., 2002). The paper reports the isolation of Malassezia species from clinical cases in dogs and its successful management.

\footnotetext{
* Part of M.V.Sc. thesis submitted by the first author to Kerala Veterinary and Animal Sciences University, Pookode, Wayanad, Kerala

1. M.V.Sc. scholar and corresponding author

(Email \&Phone: anjudaniel101969@gmail.com\& 9946329612)

2. Assistant Professor

3. Associate Professor, Dept. of Veterinary Microbiology

4. Professor and Head
}

Copyright: () 2021 Daniel et al. This is an open access article distributed under the terms of the Creative Commons Attribution 4.0 International License (http://creativecommons.org/licenses/by/4.0/), which permits unrestricted use, distribution, and reproduction in any medium, provided the original author and source are credited. 


\section{Materials and methods}

Ten dogs of different breed, age and gender that were presented to Teaching Veterinary Clinical Complex, College of Veterinary and Animal Sciences, Pookode, with clinical signs of alopecia, pruritus, erythema, hyperpigmentation, lichenification, foul odour and otitis externa suggestive of malasseziosis were subjected to detailed clinical examination. Cytological examination of skin and ear swabs were carried out by Methylene blue staining. On cytology, at least one body site having a mean of $\geq 1$ yeast organism per oil immersion field (OIF) during microscopic examination of 10 consecutive OIF with corneocytes considered positive for malasseziosis (Pinchbeck, 2002). Cultural examination was done by inoculating the samples onto Modified Dixon's Agar and incubating at $37^{\circ} \mathrm{C}$ for up to seven days (Rathnapriyaet al., 2016). Total DNA was extracted from the pure cultures of the isolates using conventional phenol - chloroform method and were subjected to polymerase chain reaction targeting large subunit ribosomal RNA gene of Malassezia spp. (Guillotet al., 2000) Dogs with malasseziosis were treated with oral itraconazole at $5 \mathrm{mg} / \mathrm{kg}$ bodyweight, orally once daily for 28 days along with supportive therapy, which included essential amino acids and herbalimmuno-stimulants. Six apparently healthy dogs were selected for the control group.Haematological and serum biochemical studies were performed.Comparison between study and control animals was done by using independent t-test.

\section{Results and discussion}

Clinical parameters were found to be within the normal range upon general clinical examination with mean respiratory rate of $27.22 \pm 1.02 / \mathrm{min}$, pulse rate of $92 \pm$ $0.6 / \mathrm{min}$ and temperature of $102.14 \pm 0.15^{\circ} \mathrm{F}$. Haematological and serum biochemical study revealed leucocytosis and mild non regenerative anaemia in affected dogs. Significantlyless Haemoglobin ( $\mathrm{Hb}$ ), Volume of Packed Red Cells (VPRC) and Mean Corpuscular Haemoglobin $(\mathrm{MCH})(\mathrm{p}<0.05)$ values were obtained in dogs with malasseziosis when compared to control group (Table 1).Takahira (2009) reported that mild to moderate non regenerative anaemia is the most common anaemia in dogs with fungal, bacterial, viral and protozoal diseases. Further, it was stated that reduced erythrocyte production and erythrocyte removal by immunologic mechanisms or oxidative damage could lead to development of anaemia in the above conditions.Significantly highvalues of TLC ( $p<0.01)$ were observed in affected dogs when compared to control group (Table 1). Hromadaetal. (2005) also observed a significant increase in total leukocyte count in dogs infected with malassezia yeasts and,whichmight be due to inflammatory changes in the skin. There is

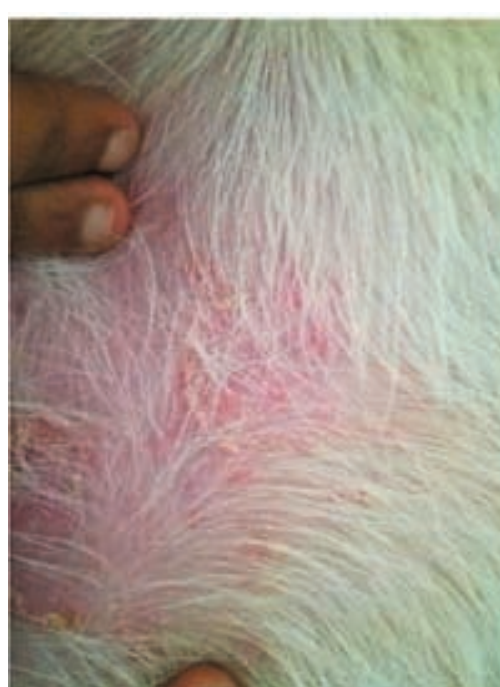

Epidermal collarette

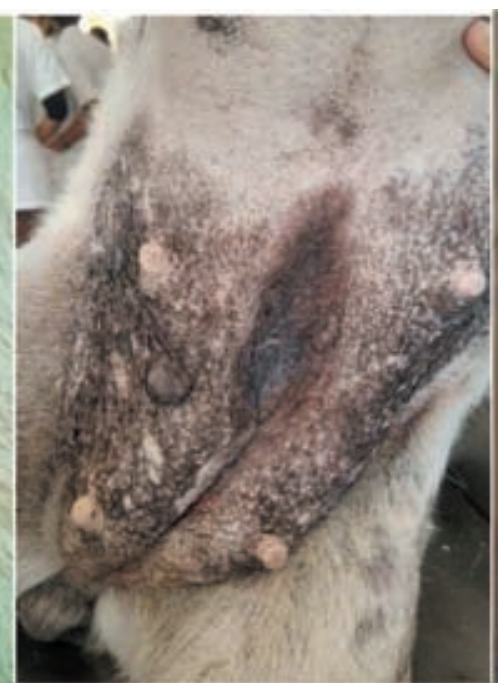

Hyperpigmentation

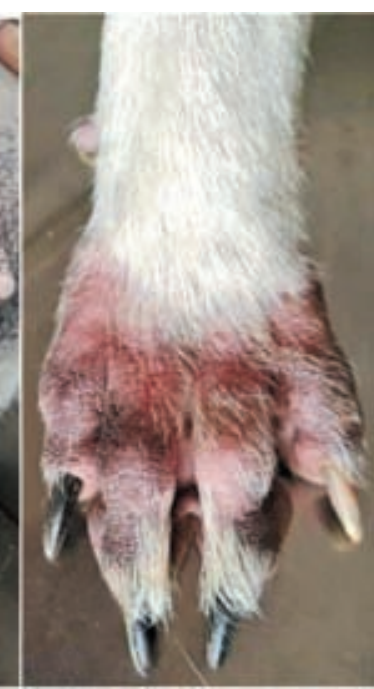

Alopecia \& Erythema

Fig. 1. Clinical manifestations of malasseziosis in dogs 


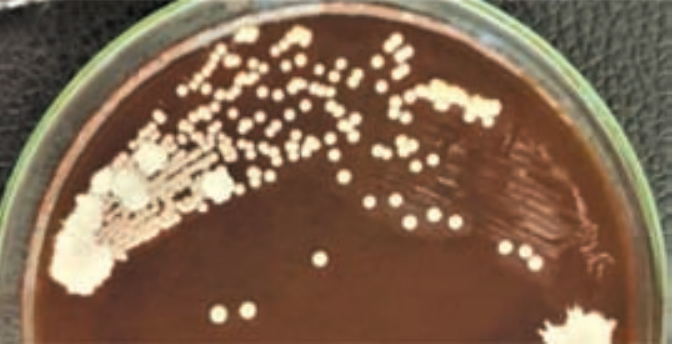

Fig. 2. Colonies of Malassezia spp. on MDA

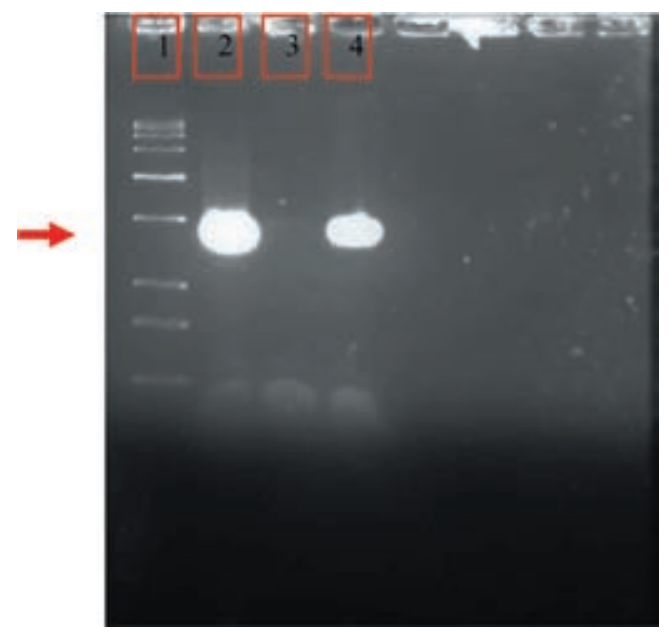

Fig. 4. Molecular detection of Malassezia spp. (Lane 1 - 100 bp ladder; Lane 2, 4 - Isolates of Malassezia spp.; Lane 3 - Negative control; Amplicon size between 541 bp and 579 bp)

no statistically significant difference in ALT, ALP, total protein, albumin and globulin values in dogs with malasseziosisin comparison with control group (Table 2). Detailed examination of the skin revealed alopecia, pruritus, erythema, hyperpigmentation, lichenification, epidermal collarettes, pustules, vesicles and nodules (Fig. 1). These findings were in accordance with Bond etal. (2020) who reported that pruritus, erythema, hyperpigmentation, malodour and traumatic alopecia were the major clinical signs in dogs with malasseziosis. Microscopic examination of acetate tape impression smears revealed the presence of Gram positive budding yeast cells. Jatavath and Kumar (2014) identified malassezia yeasts by cytology using the tapestrip technique. Impression and swab smear examinations of ten diseased dogs revealed the presence of cocci in six dogs suggestive of bacterial pyoderma. Dogs in association with

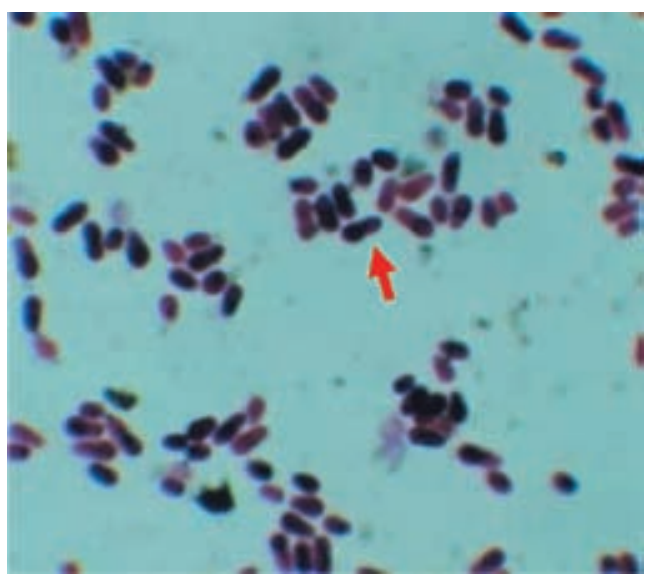

Fig. 3. Microscopic examination of colonies of Malassezia spp. using Gram's staining

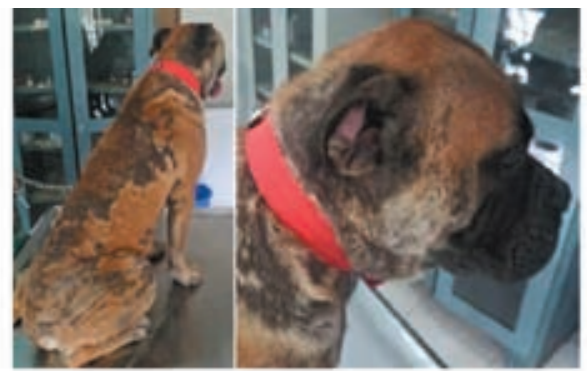

Fig. 5a.1st day

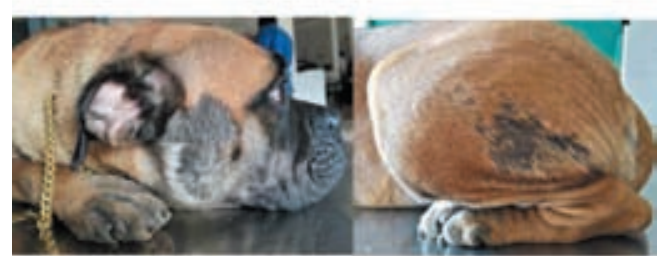

Fig. 5b. 14th day

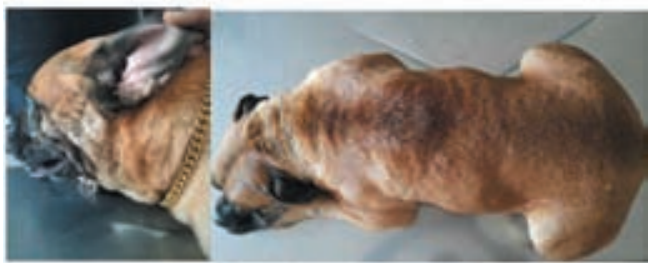

Fig. 5c. 28th day

Fig. 5. Clinical response to treatment with Itraconazole

concurrent bacterial infections were treated with antimicrobial therapy.Ten isolates suggestive of Malasseziaspp. were obtained on MDA. The colonies were cream to buff coloured with smooth, convex surface (Fig.2). Of these, seven were isolated from skin lesions of dogs and the rest were obtained from cases of otitis externa. 
Table 1. Comparison of haematology of dogs with malasseziosis and control animals

\begin{tabular}{|c|c|c|c|c|c|}
\hline \multirow{2}{*}{$\begin{array}{l}\text { SI. } \\
\text { No. }\end{array}$} & \multirow{2}{*}{ Parameter } & \multicolumn{2}{|c|}{ Mean \pm SE } & \multirow{2}{*}{ t-value } & \multirow{2}{*}{ P-value } \\
\hline & & Study Group & Control Group & & \\
\hline 1 & $\mathrm{Hb}(\mathrm{g} / \mathrm{dL})$ & $13.63 \pm 0.73$ & $16.03 \pm 0.70$ & $2.2^{*}$ & 0.046 \\
\hline 2 & PCV (\%) & $40.12 \pm 2.36$ & $48.18 \pm 1.89$ & $2.36^{*}$ & 0.033 \\
\hline 3 & TEC (x 10\% $/ \mathrm{cmm})$ & $6.40 \pm 0.3$ & $6.87 \pm 0.26$ & $1.09^{n s}$ & 0.292 \\
\hline 4 & TLC $\left(\times 10^{3} / \mathrm{cmm}\right)$ & $23.9 \pm 2.9$ & $11.85 \pm 0.66$ & $3.06^{\star \star}$ & 0.009 \\
\hline 5 & Platlet count $\left(\times 10^{3} / \mu \mathrm{L}\right)$ & $339.1 \pm 28.9$ & $274.67 \pm 25.28$ & $1.52^{\text {ns }}$ & 0.151 \\
\hline 6 & $\operatorname{MCV}(f L)$ & $63.05 \pm 2.6$ & $70.2 \pm 0.6$ & $2.08^{\text {ns }}$ & 0.056 \\
\hline 7 & $\mathrm{MCH}(\mathrm{g} / \mathrm{dL})$ & $21.3 \pm 0.59$ & $23.23 \pm 0.22$ & $2.48^{*}$ & 0.026 \\
\hline 8 & $\mathrm{MCHC}(\mathrm{pg})$ & $34.1 \pm 0.76$ & $33.2 \pm 0.2$ & $0.873^{\text {ns }}$ & 0.398 \\
\hline 9 & $\mathrm{~N}(\%)$ & $79.63 \pm 2.63$ & $76.75 \pm 1.66$ & $0.79^{\text {ns }}$ & 0.445 \\
\hline 10 & $L(\%)$ & $15.1 \pm 2.42$ & $16.97 \pm 1.79$ & $0.54^{\mathrm{ns}}$ & 0.595 \\
\hline 11 & $\mathrm{M}(\%)$ & $3.2 \pm 0.32$ & $4.55 \pm 0.44$ & $2.54^{\mathrm{ns}}$ & 0.23 \\
\hline 12 & $E(\%)$ & $2.1 \pm 0.3$ & $1.73 \pm 0.38$ & $0.78^{\text {ns }}$ & 0.446 \\
\hline
\end{tabular}

** Significant at 0.01 level $(P<0.01)$; ${ }^{*}$ Significant at 0.05 level $(P<0.05)$; ns Non-significant $(P>0.05)$

Table 2. Comparison of serum biochemical values of dogs with malasseziosis and control animals

\begin{tabular}{|c|c|c|c|c|c|}
\hline \multirow{2}{*}{ SI. No. } & \multirow{2}{*}{ Parameters } & \multicolumn{2}{|c|}{ Mean \pm SE } & \multirow{2}{*}{ t-value } & \multirow{2}{*}{ P-value } \\
\cline { 3 - 4 } & & Diseased Group & Control Group & & \\
\hline 1 & ALT (U/L) & $30.6 \pm 8.22$ & $25.16 \pm 2.13$ & $0.5^{\text {ns }}$ & 0.626 \\
\hline 2 & ALP $(\mathrm{U} / \mathrm{L})$ & $106.8 \pm 14.21$ & $77.16 \pm 7.19$ & $1.53^{\text {ns }}$ & 0.148 \\
\hline 3 & TP $(\mathrm{g} / \mathrm{dL})$ & $5.5 \pm 0.24$ & $6.11 \pm 0.12$ & $1.85^{\text {ns }}$ & 0.085 \\
\hline 4 & Albumin $(\mathrm{g} / \mathrm{dL})$ & $2.4 \pm 0.17$ & $2.88 \pm 0.08$ & $2.15^{\text {ns }}$ & 0.05 \\
\hline 5 & Globulin $(\mathrm{g} / \mathrm{dL})$ & $3.12 \pm 0.25$ & $3.23 \pm 0.05$ & $0.34^{\text {ns }}$ & 0.738 \\
\hline
\end{tabular}

ns Non-significant $(P>0.05)$

Rathnapriyaetal. (2016) and Marin et al. (2018) also successfully isolated malassezia yeasts on Modified Dixon's Agar at $37^{\circ} \mathrm{C}$ for five days with a higher isolation rate compared to Sabouraud Dextrose Agar with olive oil overlay. Microscopic examination of colonies revealed dark blue coloured footprint shaped organism on Gram's staining. Microscopically, budding yeast cells with buds attached to the mother cell by a broad base were observed (Fig. 3). All the ten isolates were positive in the PCR targeting LSU region of Malassezia spp. (Fig. 4). Affeset al. (2009) reported that the use of $\mathrm{PCR}$ method provides a sensitive and rapid identification system for Malassezia species, which can be applied in epidemiological surveys and routine practice. Clinical response to itraconazole therapy was monitored at $14^{\text {th }}$ and $28^{\text {th }}$ day of treatment. An excellent clinical response along with quick recovery (by $14^{\text {th }}$ day itself) was noticed in all the ten dogs treated with oral itraconazole. By $28^{\text {th }}$ day of treatment, all the animals showed complete recovery from all the clinical signs. Clinical response to treatment with itraconazole were shown in Fig. $5 \mathrm{a}, 5 \mathrm{~b}$ and $5 \mathrm{c}$. Haimbach (2019) reported that itraconazole given at $5 \mathrm{mg} /$ $\mathrm{kg}$ bodyweight daily for three weeks had good efficacy against malasseziainfection in dogs.

\section{Conclusion}

The present study concluded that cytological, cultural and molecular examination of clinical samples can be effectively used for diagnosis of Malassezia species. Orally 
itraconazole was found to be effective for the treatment of canine malasseziosis with excellent clinical response and quick recovery.

\section{Acknowledgement}

The authors thank the Dean, College of Veterinary and Animal Sciences, Pookode for providing facilities for conduct of the study.

\section{Conflict of interest}

The authors declare that they have no conflict of interest.

\section{References}

Affes, M., Salah, S.B., Makni, F., Sellami, H. and Ayadi, A. 2009. Molecular identification of Malassezia species isolated from dermatitis affections. Mycoses. 52: 251256.

Bond, R., Morris, D.O., Guillot, J., Bensignor, E.J., Robson, D., Mason, K.V., Kano, R. and Hill, P.B. 2020. Biology, diagnosis and treatment of Malassezia dermatitis in dogs and cats Clinical Consensus Guidelines of the World Association for Veterinary Dermatology. Vet. Dermatol. 31: 27-e4.

Guillot, J., Deville, M., Berthelemy, M., Provost, F. and Gueho, E. 2000.A single PCRrestriction endonuclease analysis for rapididentification of Malasseziaspecies. Lett. Appl. Microbiol. 31: 400-403.

Haimbach, B., 2019. Malassezia Dermatitis. In: Small AnimalDermatology for
Technicians and Nurses. WileyBlackwell, 45-52.

Hromada, R., Posivak, J., Posivakova, S., Sasakova, N., Culenova, K., Hromadova, Z., Bajova, V., Mojzisova, J. and Ondrasovic, M. 2005. Malasseziosis and immunity. Folia Vet. 49: 37-39.

Jatavath, J. and Kumar, K.S. 2014. Scanning electron microscopic (SEM) aspect of Malasseziapachydermatis isolated from dog. Int. J. Agric. Sci. Vet. Med. 2: 128131.

Marin, J. C. G., Rojas, F. B. and Escobar, A. J. G. 2018. Physiological and molecular characterization of Malasseziapachydermatisreveals no differences between canines and their owners. Open J. Vet. Med. 8: 87- 105.

Pinchbeck, L. R., Hillier, A., Kowalski, J. J. and Kwochka, K. W. 2002.Comparison of pulse administration versus once daily administration of itraconazole for the treatment of Malasseziapachydermatis dermatitis and otitis in dogs. J. Am. Vet. Med. Assoc. 220: 1807-1812.

Rathnapriya, N., UshaKrishnan, K. and Janaki, C. 2016. Isolation of Malassezia yeast using Modified Dixon's Agar from Pityriasisversicolor lesions. Indian $\mathrm{J}$. Basic Appl. Med. Res. 5:123-129.

Takahira, R.K.Chronic NonregenerativeAnemia: A Challenge?. In:Proceedings of $34^{\text {th }}$ World Small Animal Veterinary Association World Congress; $21^{\text {st }}$ to $24^{\text {th }}$ July, 2009, Sao Paulo, Brazil.WSAVA. 